\title{
Student Perceptions of the Use of Multimedia for Online Course Communication
}

\author{
Jaclyn Krause, Laura Portolese and Julie Bonner \\ Central Washington University
}

\begin{abstract}
A great deal of research exists in the use of multimedia communications in online classrooms as a means of furthering student engagement. However, little research exists that examines the perceptions of students when such technologies are used. Additionally, it is unclear that students are likely to engage in the use of such technologies when available. This research explores the perceptions of 69 students taking both online and hybrid undergraduate project management courses. Specifically, the study seeks to explore how students experienced the use of multimedia by their instructor and classmates in both online announcements and discussions, as well as whether these same students used or would be likely to use multimedia for similar communications. Finally, student perceptions of social presence, the degree to which one is perceived as a real person in computer-mediated communication (Gunawardena, 1995), are examined. The results of the study indicate that while students overwhelming enjoy the instructor's use of multimedia communication, they are unlikely to engage in using these technologies themselves. A discussion of these results and recommendations for further research complete this paper.
\end{abstract}

Keywords: online classes, multimedia communications, social presence

Krause, J., Portolese, L., \& Bonner, J. (2017). Student perceptions of the use of multimedia for online course communication. Online Learning, 21(3), 36-49 doi:

10.24059/olj.v21i3.1198

\section{Introduction}

While there are numerous best practices that suggest how instructors should engage with students in online discourse, there is little known about students' attitudes and perceptions of these practices. Some best practices include using small discussion groups (Dixson, 2010), rapport and trust building (Ragan, 2007), student-led discussions (Pelz, 2004), promoting constructivist thinking through stimulating questions, brainstorming, and comparing ideas (Muilenburg \& Berge, n. d.), and building a warm and inviting learning community by welcoming students, posting personal introductions, and providing lots of encouragement (Ragan, 2007). Results of studies in these areas suggest that students are more satisfied with their online experience when such approaches are implemented. However, faculty still lament that online discussions often lack significant engagement and quality (Morrison, 2012).

Significant research exists in the use of multimedia in online courses that use both synchronous and asynchronous technologies. Computer-mediated technologies in online courses have been available for many years and include videos, web chats, instant messaging, and synchronous classroom environments. However, little is known as to whether students value these 
tools as a means of engaging with class peers and instructors, or whether these tools help to "humanize" the instructor or peers to students. Less is known whether students themselves will choose to use these tools as a means of participating in discussions, thereby increasing engagement.

\section{Literature Review}

The review of current research focuses on three factors in online class discussions; best practices, the use of computer-mediated technologies, and the importance of both instructor and social presence.

\section{Online discussion best practices}

While there are obvious differences in an online environment versus a face-to-face one, relationship building is key to a successful environment no matter the modality. For instance, research suggests that communication with intention matters (Cerniglia, 2011). Communicating with intention includes how an instructor communicates with the written word. For example, feedback on assignments should vary based on the student's ability (Cerniglia, 2011). Written communication strategies include timeliness, having a student feel valued, and explicitly asking questions of the student in order to encourage a conversation (Cerniglia, 2011).

In addition to how instructors communicate through the written word, a teacher's effectiveness level increases with video communications (Cerniglia, 2011). For example, sometimes writing can be overwhelming to a student to read, however a video can create a more engaging environment not only for the student but for the instructor (Cerniglia, 2011). Video feedback can also enhance engagement through more timely and easily understandable feedback (Crook, Maw, Laweson, Drinkwater \& Lundgvist, 2012). Supporting this research, Dias and Trumpy (2014) provided timely audio and video feedback - either personal or general feedback enhanced social presence and student's perception of instructor engagement was higher with these methods, as opposed with just use of the written word to communicate with students.

Finally, discussion boards are an effective tool for learning; however, instructors need creativity in how discussion boards are implemented and used. Not only should discussion boards be open ended in nature, but other considerations include encouraging students to "extend, expand on, question, or challenge ideas" (Cerniglia, 2011, p. 58). Any strategy that allows the expansion of student experiences and stories in the discussion boards deepens the learning and helps to focus the conversation (Cerniglia, 2011). In addition, Sung and Mayer (2012) indicate discussion boards can be helpful for faculty in creating positive social presence for themselves, but "social sharing" can build community.

The challenge with discussion boards is balancing how time consuming discussion boards can be for students and instructors compared to the learning the discussion board is attempting to demonstrate (Goldman, 2011). The success of the online learning environment is highly dependent on the quality implementation of online discussion boards (Maddix, 2012). Unlike a physical classroom, the ability for every student to participate is an advantage of online learning (Maddix, 2012). Discussion guidelines include a focus on design and development of the questions, setting up expectations on responses, and launching and managing the discussion (Goldman, 2011). In giving time and attention to a discussion guideline document, an instructor can implement the best 
balance between the learning experience of the student, the quality of the discussion and learning, and the workload for all parties (Goldman, 2011).

One element that is critical for the instructor in the discussion board learning environment is the clear expectation of a substantive interaction (Maddix, 2012). Substantive interactions would include a focus on three elements of timeliness, effectiveness of writing, and how the student is expressing the knowledge elements necessary in learning the material (Maddix, 2012). Faculty can increase their effectiveness in learning how to ask good questions through using Bloom's Taxonomy, the Socratic Method, showing a different way of looking at a topic by playing devil's advocate, and relating ideas to personal experience (Maddix, 2012).

Essentially, through focusing on the discussion board elements, a learning community is formed (Hilton, 2013; Maddix, 2012). Learning communities are strengthened by how relationships are built in an online environment and the tools available to the student and the faculty member in the learning management system (Hilton, 2013). A faculty can enhance the ability to encourage different viewpoints by demonstrating contrasting viewpoints in sources of information and demonstrating that all viewpoints are part of the whole and contribute to the full understanding of a topic (Hilton, 2013).

Ultimately, the quality of discussion boards is under scrutiny as a measure of assessing student thinking (Williams, Jaramillo \& Pesko, 2015). Research suggests that the ability for students to obtain a higher level of discourse is dependent upon the ability for an instructor to explicitly express expectations on the quality of these interactions (Williams, Jaramillo \& Pesko, 2015). These expectations will be reinforced through grading expectations, including commenting on a student's ability to go beyond socializing to convergent and divergent thinking by providing examples of when these levels of thinking are achieved (Williams, Jaramillo \& Pesko, 2015). To increase the effectiveness of discussion boards in learning, a higher level of engagement is required by all parties in the learning experience.

\section{Computer-mediated technology}

Using the computer to facilitate human communications can have both advantages and disadvantages in online classrooms. Frequently, student engagement is measured in terms of the number of interactions in the classroom (Dixson, 2010). However, the quality of the content, specifically, the instructor posts has been shown to be an equally important factor. While instructor facilitation may help lead the discussions and encourage a deeper connection with the content, students more fully engage with their peers in the discussions (Dixson, 2010). The quality of content seems to be an important part of the student engagement in the online discussions (Canney, 2015; Lowes, Lin, Wang, 2007). In addition, Lowes et. al (2007) confirmed that the quality of the interaction between instructor and student helped further engagement in online discussions. Additional information as well as provocative or probing questions were two examples of techniques that furthered engagement (Canney, 2015).

\section{Social presence theory and application}

Dixson (2010) indicates that students that were highly engaged with other students in their course were more satisfied with their course experiences. The instructor role was that of facilitator, encouraging a deeper level of discussion. Social presence theory classifies various types of communication along a continuum. Sallnas (2000) defines social presence as the degree of awareness of the other person in any given communication. For example, face-to-face 
communication has the highest social presence, while written or text-based communication has the least social presence. The social presence, in the online classroom, includes the extent to which the instructor is perceived as a real person, as opposed to a webmaster. This presents an interesting challenge to online instructors: how to create a social presence online while utilizing mediums that may be limiting. The role of an online instructor is that of a facilitator, organizer, and manager (Cooper \& Hendrick-Keefe, 2001). Understanding this is key to understanding the use of multimedia in creating social presence in the online classroom.

In an online classroom, there are eight possible social presence cues identified by Abdullah (1999) and Rourke, et al. (2001). These cues include humor, emotions, self-disclosure, support or agreement for an idea, addressing people by name, greetings, complimenting another's idea, and illusions of a physical presence.

- Humor: Use of humor in the online classroom, such as through announcements or emails can reduce social distance and conveys goodwill (Aragon, 2003).

- Emotions: Showing emotions to students such as happiness can add clarity to a message and forge connections (Scollins-Mantha, 2008). Sharing of feelings and emotions using emoticons in emails to students, for example, is a way to do this in writing ( $\mathrm{Tu}$ \& McIsaac, 2002).

- Self-disclosure: While instructors may hesitate to share personal information, sharing of some personal information can build the online relationship between student and instructor. For example, noting in an email your plans for the weekend "I am going kayaking, do you have big plans for the weekend?" posting pictures of the instructor performing his or her favorite activity can also heighten social presence, (Savery, 2005).

- Support or agreement for an idea: Through online feedback such as discussion boards and allowing students to peer review posts and assignments, the instructor can generate social presence in this manner.

- Greetings and addressing students by name: Rather than simply replying to an email or communication, saying, "Hi Lisa," or "Good afternoon, Roger" can create greater social presence online.

- Complimenting: Telling students of a job "well done" or "keep up the good work" on assignment feedback can enhance instructor social presence, and develop confidence and connection in the online classroom (Scollins-Mantha, 2008).

- Illusions of a physical presence: Social presence in this manner (Johnson \& Keil, 2002) can be accomplished through synchronous tools such as audio or video recordings, feedback, and lectures. Instructors must understand the isolation felt by students when communication lags (Tu \& McIsaac, 2002).

Based on this information, the focus of this paper is an important topic - how are student attitudes and perceptions affected by using multimedia tools? The purpose statement and research will be presented in the forthcoming sections. 


\section{Methods}

The purpose of this quantitative study was to explore the attitudes and perceptions of students to the use of multimedia in online class discussions and announcements posted by their instructor. The research question guiding this study was "what are student attitudes and perceptions of the use of multimedia tools for announcement and discussions posts in online and hybrid courses?"

\section{Study Design}

The intention of this study was to uncover the attitudes and perceptions of students to the use of multimedia, both voice and web camera enabled communication in online class announcements and discussions. A survey-based approach was used to gather data and simple statistical analyses were performed as a means of exploring these responses. Students in three undergraduate project management classes at a university in central Washington State were the subject of this study. Two classes were fully online and one was offered as a hybrid class. Approval had been obtained by the institutional review board before proceeding with data collection.

Five questions were added to the end of term student course surveys. These questions were intended to gauge the student's review of the multimedia responses posted by the instructor, as well as their own use of such multimedia tools. Finally, students were asked if they felt that the use of multimedia, either voice or web camera helped them identify with their instructor or classmates more as real individuals. Appendix A contains the questions.

The university where the study took place uses Canvas as the learning management system. Canvas allows the recording of both audio and video as an alternative to text for announcements, discussion responses, and instructor feedback. Both instructors and students may use these technologies without limitation. At the beginning of the course, the instructor encouraged students to participate by engaging in discussions using the multimedia method of their choosing. Instructions were provided to students and regular encouragement was given throughout the course.

\section{Methodology}

The study questions were added to the standard end of course student evaluation survey and students were incentivized to complete the evaluations by earning a small number extra credit points when the overall class percentage of completion hit $80 \%$. The data were obtained from institutional effectiveness and processed through SPSS.

\section{Results}

The student response rates for the three classes are listed in Table 1.

\begin{tabular}{|c|c|c|c|c|}
\hline & & Frequency & Percent & $\begin{array}{c}\text { Valid } \\
\text { Percent }\end{array}$ \\
\hline \multirow[t]{4}{*}{ Valid } & ADMG 374 On Campus & 27 & 48.2 & 48.2 \\
\hline & ADMG 374 Online & 20 & 35.7 & 35.7 \\
\hline & IT 376 Online & 9 & 16.1 & 16.1 \\
\hline & Total & 56 & 100.0 & 100.0 \\
\hline
\end{tabular}

Table 1. Number of participants by class and modality 

as follows:

The results for each question were analyzed cumulatively across the three courses and are

Question 1: During this term, your instructor used multimedia methods of communication, specifically voice recordings and web camera recordings to communicate announcements and participate in the class discussions. How often did you view or listen to these recordings?

With $\mathrm{N}=56$ students responding to this question, over half the students surveyed (31) reported that they Always or Frequently viewed or listened to multimedia posts. Table 2 contains the student responses.

\begin{tabular}{llr|r|r|} 
& & & \multicolumn{1}{c|}{ Valid } \\
& Frequency & Percent & Percent \\
\hline Valid & Never & 6 & 10.7 & 10.7 \\
\cline { 2 - 5 } Rarely & 4 & 7.1 & 7.1 \\
\cline { 2 - 5 } Occasionally & 15 & 26.8 & 26.8 \\
\hline Frequently & 17 & 30.4 & 30.4 \\
\hline Always & 14 & 25.0 & 25.0 \\
\hline \multicolumn{2}{r|}{ Total } & 56 & 100.0 & 100.0 \\
\hline
\end{tabular}

Table 2. Responses to Question 1

Question 2: If you listened to or viewed these recordings, did you find them useful?

With $\mathrm{N}=55$ students responding to this question, again over half of those responding (37) indicated that the multimedia was useful. Table 3 contains the responses.

\begin{tabular}{|c|c|c|c|c|}
\hline & & Frequency & Percent & $\begin{array}{c}\text { Valid } \\
\text { Percent }\end{array}$ \\
\hline \multirow[t]{8}{*}{ Valid } & Never Listened & 4 & 7.1 & 7.3 \\
\hline & Rarely Useful & 3 & 5.4 & 5.5 \\
\hline & Occasionally Useful & 11 & 19.6 & 20.0 \\
\hline & Frequently Useful & 21 & 37.5 & 38.2 \\
\hline & All were useful & 16 & 28.6 & 29.1 \\
\hline & Total & 55 & 98.2 & 100.0 \\
\hline & Missing & 1 & 1.8 & \\
\hline & Total & 56 & 100.0 & \\
\hline
\end{tabular}

Table 3. Responses to Question 2

Question 3: During this term, your instructor encouraged you to use multimedia, specifically voice recordings and web camera recordings to respond to announcements or discussion posts. How often did you participate by using voice recordings or web camera recordings?

Here, $N=56$ students responded to this question and more than half (39) admitted that they Never or Rarely used this technology themselves to respond to discussions or announcements. Table 4 contains the responses. 


\begin{tabular}{ll|r|r|r|} 
& Frequency & Percent & Valid Percent \\
\hline Valid & 24 & 42.9 & 42.9 \\
\cline { 2 - 5 } Never used & 15 & 26.8 & 26.8 \\
\cline { 2 - 5 } Rarely used & 5 & 8.9 & 8.9 \\
\hline Occasionally used & 7 & 12.5 & 12.5 \\
\hline Frequently used & 5 & 8.9 & 8.9 \\
\hline Always used & 56 & 100.0 & 100.0 \\
\hline
\end{tabular}

Table 4. Responses to Question 3

Question 4: If you participated using voice recording or web camera recordings, did you enjoy the experience?

While 19 students admitted that they did not participate in discussions, those that did Somewhat Enjoyed or Enjoyed the experience (30). Table 5 contains the responses.

\begin{tabular}{ll|r|r|r|} 
& Frequency & Percent & Valid Percent \\
\hline Valid & 19 & 33.9 & 34.5 \\
\cline { 2 - 5 } & I did not participate & 6 & 10.7 & 10.9 \\
\cline { 2 - 5 } I did not enjoy the experience & 13 & 23.2 & 23.6 \\
\hline I somewhat enjoyed the experience & 17 & 30.4 & 30.9 \\
\cline { 2 - 5 } & I enjoyed the experience & 55 & 98.2 & 100.0 \\
\cline { 2 - 5 } Total & 1 & 1.8 & \\
\hline Missing & Total & 56 & 100.0 & \\
\hline
\end{tabular}

Table 5. Responses to Question 4

Question 5: If you used multimedia tools, either by listening to or viewing the recordings or by recording responses yourself, did you feel the experience helped you relate to your faculty or fellow classmates as real people?

Of the $\mathrm{N}=56$ students that responded to this question, the majority (37) reported that the multimedia recordings were Somewhat helpful and Definitely Helpful in helping them relate to their instructor and classmates as real people. Table 6 contains the responses.

\begin{tabular}{ll|r|r|r|} 
& Frequency & Percent & Valid Percent \\
\hline Valid & 9 & 16.1 & 16.1 \\
\cline { 2 - 5 } & I did not use these tools & 10 & 17.9 & 17.9 \\
\cline { 2 - 5 } & I did not feel them helpful in relating & 17 & 30.4 & 30.4 \\
\cline { 2 - 6 } I found them somewhat helpful in relating & 20 & 35.7 & 35.7 \\
\hline & They were definitely helpful in relating & 56 & 100.0 & 100.0 \\
\hline
\end{tabular}

Table 6. Responses to Question 5 


\section{Possible Errors}

Internal and external validity issues may stem from the classes chosen to study, feeling toward the instructor, and overall student performance. Different results may occur if these were not online or hybrid courses, but fully on-campus courses. In addition, there may be variance between student's attitudes about school and performance online and hybrid students. It is questionable whether this study could be generalized over long periods of time, and the classes studied may not be a representation of the general population.

\section{Discussion}

Two distinct findings were identified in these results. The first was that while students admitted to watching these multimedia posts ( 31 of 56), found them useful ( 37 of 55) and enjoyed the experience (39 of 56), students chose not to participate in using multimedia for their own responses, even though instructions and encouragement were provided throughout the course and the technology was readily available within the learning management system. While students responded positively to the experience, they did not themselves engage with these tools. This finding may support the construct of trust as a best practice for discussions (Kelly, 2008). Students who feel uncertain or vulnerable may be unlikely to take risks.

Second, while these same students admitted that they did not participate in the use of multimedia tools themselves, they believed that these tools helped them relate more to their instructor and classmates as real people (37 of 56). This was especially interesting as it represents an attitude that students may wish to have a more intimate relationship with their instructor, but on their own terms. Using multimedia can help facilitate community among the students (University Teaching \& Learning Center, The George Washington University, n.d.; Ragan, 2007). A mixed methods study by Mandernach (2009) indicated in the quantitative data that there was no significant difference in student engagement or learning when multimedia was used in the online class, yet in the qualitative responses these same students felt more "engaged." This study seems to support our finding; while students value multimedia, there is a reluctance to use these tools themselves. Research performed by Miller (2013) may explain this. While students may not participate in the multimedia, it still gives the illusion of social presence, thereby adding value regardless. "Social presence is the ability of participants to identify with the group, communicate in a trusting environment, and develop social relationships by way of expressing their individuality." (Wilcoxon, 2011, para. 8), lending more importance to the use of multimedia to help establish social presence, both instructor presence and student presence.

So far, the research shows students find the multimedia addressed in this study useful, and it creates greater social presence, but the question remains, why don't they use the multimedia tools provided to them? Some possibilities are lack of comfort with technology, a lack of understanding of how their grade may be impacted by using multimedia for discussion responses, and a tendency to desire maximizing their time and approach class completion in a transactional manner.

First, lack of comfort using the technology, and/or the fact students may be unsure of how to use the technology could be a reason why students do not use the multimedia, despite the advantages the student finds with such tools. It is important to note $14 \%$ of all higher education students are taking $100 \%$ of their courses online while another $14 \%$ takes some of their courses online (Allen \& Seaman, 2014). In addition, research shows high comfort levels with technology, 
with $97.8 \%$ of students owning a mobile phone. In addition, students who are younger than 20 report frequent engagement with instant messaging, texting, use of social network sites, and downloading or streaming TV and video (Jones, 2012). Those students under 20 are comfortable using many methods of technology, while of those students over 35, 78.5\% never use social networking sites and other similar forms of technology. It would be expected with the high frequency of online course offerings combined with comfort levels in technology, students would not find classroom and learning management system technology a challenge to use. Further, one would expect students would be comfortable using the multimedia options available to them.

Early research by Rodrigeuz Ooms \& Montanez (2008) shows comfort with technology is not related to student satisfaction in an online course, but rather, comfort level is related to the individual student motivation to learn how to use the technology. This could be a possible reason for not wanting to use the technology_motivation to learn something new.

Also, students of all ages may be comfortable using technology from a personal perspective, but not from a classroom perspective due to lack of motivation, rather than comfort levels. In addition, the research study addressed in this paper did not measure demographics, but perhaps a larger share of students in the courses were non-traditional students, less comfortable with technology on the whole as Jones (2012) research suggests. The authors believe that comfort level with use of the multimedia technology is likely not a factor in the fact they don't use the multimedia, but instead it may be simple lack of motivation to use it, despite students seeing the benefit of such multimedia technology.

Second, students want clear expectations of how assignments will be graded (Mupinga, Nora, \& Yaw, 2006). Additionally, grading discussion responses tends to be more subjective and therefore more difficult to define quality expectations (Beckett, Amaro-Jiménez, and Beckett, 2010). With respect to expectations, students come to online classes with various learning styles and preferences of how they engage with course material (Mupinga, Nora, \& Yaw, 2006). These preferences may manifest themselves in active vs. inactive learning or visual vs. auditory preferences. In a study conducted by Mupinga et al., students identified four key needs for support in their online classes: "technical help, flexible and understanding instructors, advanced course information, and sample assignments" (p. 187). It may be possible that students would prefer to hear examples of discussion responses that would meet quality expectations before they commit to trying multimedia for a response. One open-ended response from a student surveyed indicated that "Sometimes it is difficult to understand exactly what an instructor is looking for without being in class ..." (p. 187). Examples may help fill these gaps.

Beckett, Amaro-Jiménez, and Beckett (2010) found that students may need clear instructions on how to complete the assignment and clear evidence of how the assignment will be graded. As a result, it has been suggested that one way to avoid the subjectivity involved in grading discussion posts is to use rubrics (Robins, 2016). While rubrics may help avoid the subjectivity of grading, Robins suggests that the use of strong rubrics without a strong instructor social presence may lead students to become apathetic, believing that the discussion is simply a burdensome task. Rubrics and instructor social presence, specifically through the mimicking of excellent examples will help students see more meaningful performance expectations. However, this still may not be enough to encourage students to engage in using social media for discussion responses unless specific performance measures are addressed through assignment instructions or examples. Students may simply lack the confidence with the process of public speaking to believe that they will successfully meet quality performance expectations. 
Finally, according to Brilleslyper, Ghrist, Holcomb, Schaubroeck, Warner and Williams (2012), students tend to focus on the points accumulation within a class, thus, they tend to not focus on learning outcomes. It is possible that we design courses for learning, but the points becomes the overriding goal of the student (Kohn, 1999). This focus on points can often lead to the student that argues over a grade rather than the learning of the objectives.

In addition, in a transactional approach to learning, a student will often only ask questions that are related to deliverables and the requirements of those deliverables, and not demonstrate an inquisitive learning approach in their questions of faculty (Farias, Farias, \& Fairfield, 2010). If you hear a student asking about word count, or how many pages to write, or is there an opportunity for extra credit, then these are transactional based, grade concern questions - not learning questions.

An interesting statistic was discovered by Maats and O'Brien (2012) where research was conducted on the grade versus learning dilemma. They found that $90 \%$ of students wanted a good grade, and only $6 \%$ cared about the learning. This highlights the fact that grades may not be the motivator that we think they are for learning. Thus, faculty should find ways to refocus students on learning and connections in the classroom rather than focusing solely on the grade. If faculty can move the needle on learning and natural curiosity then student behavior can move from a transactional process to a transformational process.

Additional research might further address the reasons students don't use technology and seek student perceptions. Additionally, a larger population of students, multiple instructors, and a diverse selection of courses is recommended to generalize this study. 


\section{References}

Abdullah, M. H. (1999). An examination of social presence cues in online conferences. Doctoral dissertation, Indiana University. Dissertation Abstracts International, 60(11).

Allen, I. E. \& Seaman, J. (2014). Online report card: Tracking online education in the United States. Retrieved from http://onlinelearningsurvey.com/reports/onlinereportcard.pdf

Beckett, G., Amaro-Jiménez, C., and Beckett, K. (2010). Students' use of asynchronous discussions for academic discourse socialization, Distance Education, 31(3), 315-33. DOI: http://dx.doi.org/10.1080/01587919.2010.513956

Brilleslyper, M., Ghrist, M., Holcomb, T., Schaubroeck, B., Warner, B., \& Williams, S. (2012). What's the point? the benefits of grading without points. Primus : Problems, Resources, and Issues in Mathematics Undergraduate Studies, 22(5), 411-427.

Cerniglia, E. G. (2011). Modeling best practice through online learning: Building relationships. YC Young Children, 66(3), 54-56, 58-59.

Canney, C. (2015). Elements that affect student engagement in online graduate courses (Doctoral dissertation). Retrieved from ProQuest.

Cooper, H., \& Keefe, C. (September 2001). Preparation of teachers of visually impaired students via distance. Journal of Visual Impairment \& Blindness, 95(9) 563-566.

Crook, A., Mauchline, A., Maw, S., Lawson, C., Drinkwater, R., Lundqvist, K., ... \& Park, J. (2012). The use of video technology for providing feedback to students: Can it enhance the feedback experience for staff and students?.Computers \& Education, 58(1), 386-396.

Dias, L. P., \& Trumpy, R. (2014). Online instructor's use of audio feedback to increase social presence and student satisfaction. Journal of Educators Online, 11(2).

Dixson, M. D. (2010). Creating effective student engagement in online courses: What do students find engaging? Journal of the Scholarship of Teaching and Learning, 10(2), 1-13.

Farias, G., Farias, C. M., \& Fairfield, K. D. (2010). Teacher as judge or partner: The dilemma of grades versus learning. Journal of Education for Business, 85(6), 336-342.

Goldman, Z. (2011). Balancing quality and workload in asynchronous online discussions: A winwin approach for students and instructors. Journal of Online Learning and Teaching, 7(2), 313.

Gunawardena, C. N., \& Zittle, F. J. (1997). Social presence as a predictor of satisfaction within a computer mediated conferencing environment. American Journal of Distance Education, $11(3), 8-26$. 
Hilton, J. T. (2013). Digital critical dialogue: A process for implementing transformative discussion practices within online courses in higher education. Journal of Online Learning and Teaching, 9(4), 602 .

Jones, C. (2012). Networked learning, stepping beyond the net generation and digital natives. In: Dirckinck-Holmfeld, Lone; Hodgson, Vivien and McConnell, David eds. Exploring the Theory, Pedagogy and Practice of Networked Learning. New York: Springer, pp. 27-41.

Kelly, R. (2008, August 10). Creating trust in online education - faculty focus. Retrieved from http://www.facultyfocus.com/articles/creating-trust-in-online-education/

Kohn, A. (1999). From degrading to de-grading. High School Magazine, 6(5), 38-43. Retrieved from http://www.alfiekohn.org/articles.htm

Krause, J., Tucker, J. P., \& YoungGonzaga, S. (2015). The role of semantics in knowledge and learning transfer in online discussion forums. British Journal of Education, Society \& Behavioural Science, 10(2), 1-12.

Lowes, S., Lin, P., \& Wang, Y. (2007). Studying the effectiveness of the discussion forum in online professional development courses. Journal of Interactive Online Learning, 6(3), 181 - 210. Retrieved from http://www.ncolr.org/jiol/issues/pdf/6.3.3.pdf

Maats, H. and O'Brien, K. (2012). The Straight-A Conspiracy: Your Secret Guide to Ending the Stress of School. Los Angeles: 368 Press, LLC

Maddix, M. A. (2012). Generating and facilitating effective online learning through discussion. Christian Education Journal, 9(2), 372-385.

Mandernach, J. (2009). Effect of instructor-personalized multimedia in the online classroom. The International Review of Research in Open and Distributed Learning, 10(3). Retrieved from http://www.irrodl.org/index.php/irrodl/article/view/606/1263

Miller, N. B. (2013). Student access of supplemental multimedia and success in an online course. American Journal of Distance Education, 27(4), 242-252.

Muilenburg, L. and Berge, Z. L. (2000). A framework for designing questions for online learning. DEOSNEWS, 10(2). Retrieved from

http://learningdesign.psu.edu/assets/uploads/deos/deosnews10 2.pdf

Mupinga, D. M., Nora, R. T., \& Yaw, D. C. (2006). The learning styles, expectations, and needs of online students. College Teaching, 54(1), 185-189. doi:10.3200/ctch.54.1.185-189.

Morrison, D. (2012). Online learning faculty reveal top 5 annoying online student complaints. Retrieved from: http://www.geteducated.com/elearning-education-blog/online-learningfaculty-reveal-top-5-annoying-online-student-complaints/

Pelz, B. (2004). (My) Three principles of effective online pedagogy. Journal of Asynchronous Learning Networks, 8(3), 103-116. 
Ragan, L. (2007). Best practices in online teaching: Create a warm and inviting atmosphere to build a learning community. Retrieved from http://cnx.org/content/m14877/latest/

Robins, S. (2016). Discussion bored? Create engaging online dialogue-based learning through principles of social media and effective instruction. Perspective 16(1). Retrieved from https://www.byui.edu/Documents/instructional_development/Perspective/Winter\%20201 6/SETH\%20ROBINS\%20-\%20DISCUSSION\%20BORED.pdf

Rodriguez, M.C., Ooms, A \& Montanez, M. (2008). Students' perceptions of online-learning quality given comfort, motivation, satisfaction, and experience. Journal of Interactive Online Learning, 7(2), 105-125.

Sallnas, E.L., Rassmus-Grohn, K., \& Sjostrom, C. (2000). Supporting presence in collaborative environments by haptic force feedback. ACM Transactions on Computer-Human Interaction, 7(4), 461-476.

Savery, J. (2005). BE VOCAL: Characteristics of successful online instructors. Journal of Interactive Online Learning, 4(2), 141-152.

Scollins-Mantha, Brandi, (2008). Cultivating social presence in the online learning classroom: A literature review with recommendations for practice. International Journal of Instructional Technology and Distance Learning, 5(3), 1-15.

Sung, E. \& Mayer, R. (2012). Five facets of social presence in online education. Computers in Human Behavior, 28(5), 1738-1747.

Tu, C., \& McIsaac, M. (2002). The relationship of social presence and interaction in online classes. American Journal of Distance Education, 16(3), 131-150.

University Teaching \& Learning Center, The George Washington University. (n.d.). Building community and interaction online. Retrieved from https://tlc.provost.gwu.edu/buildingcommunity-and-interaction-online

Williams, S. S., Jaramillo, A., \& Pesko, J. C. (2015). Improving depth of thinking in online discussion boards. Quarterly Review of Distance Education, 16(3), 45.

Wilcoxon, K. (2011, October 3). Building an online learning community. Retrieved from http://www.learningsolutionsmag.com/articles/761/building-an-online-learningcommunity 
Appendix A

1. During this term, your instructor used multimedia methods of communication, specifically voice recordings and web camera recordings to communicate announcements and participate in the class discussions. How often did you view or listen to these recordings?

$1=$ I never listened to or viewed these recordings

$2=$ I rarely listened to or viewed these recordings

$3=$ I occasionally listened to or viewed these recordings

$4=$ I frequently listened to or viewed these recordings

$5=$ I always listened to or viewed these recordings

2. If you listened to or viewed these recordings, did you find them useful?

$1=\mathrm{I}$ never listened to or viewed these recordings

$2=$ I rarely found the recordings useful or helpful

$3=$ I occasionally found the recordings useful or helpful

$4=$ I frequently found the recordings useful or helpful

$5=\mathrm{I}$ found all of the recording to be useful and helpful

3. During this term, your instructor encouraged you to use multimedia, specifically voice recordings and web camera recordings to respond to announcements or discussion posts. How often did you participate by using voice recordings or web camera recordings?

$1=$ I never used multimedia to respond to announcements or discussions posts

$2=$ I rarely used multimedia to respond to announcements or discussions posts

$3=$ I occasionally used multimedia to respond to announcements or discussions posts

$4=$ I frequently used multimedia to respond to announcements or discussions posts

$5=$ I always used multimedia to respond to announcements or discussions posts

4. If you participated using voice recording or web camera recordings, did you enjoy the experience?

$1=$ I did not use multimedia to respond to announcements or discussions posts

$2=$ I did not enjoy the experience

$3=$ I somewhat enjoyed the experience

$4=\mathrm{I}$ enjoyed the experience

5. If you used multimedia tools, either by listening to or viewing the recordings or by recording responses yourself, did you feel the experience helped you relate to your faculty or fellow classmates as real people?

$1=\mathrm{I}$ did not use multimedia in the class

$2=$ I participated in the multimedia experience. However, I did not feel the experience helped me relate to my faculty or fellow classmates as real people?

3 = I participated in the multimedia experience. I felt the experience helped me somewhat relate to my faculty or fellow classmates as real people.

$4=$ I participated in the multimedia experience. I felt the experience definitely helped me relate to my faculty or fellow classmates as real people. 